\title{
Photosensitive Sensors in Automated Systems
}

\author{
Alijanov Donyorbek Dilshodovich*, Boltaboyev Isroiljon Maxammatismoilovich** \\ PhD, Andijan Machine-building institute, Uzbekistan.
}

*Corresponding Author: D.D. Alijanov PhD, Andijan Machine-building institute, Uzbekistan.

\begin{abstract}
The use of photosensitive sensors in automated systems increases the accuracy of the system by ensuring its stability. The high quality of the transition processes plays an important role in the optimal operation of the system.
\end{abstract}

Keywords: photosensitive, sensors, automated system, APV.

The primary converter that measures the physical quantity measured in automated systems is called the automatic converter element. The automatic converter element consists of four different structural designation schemes (Table 1):
a) Simple one-time (primary) direct change;
b) Sequential direct change;
c) Differential scheme;
d) Compensation scheme.

Table 1

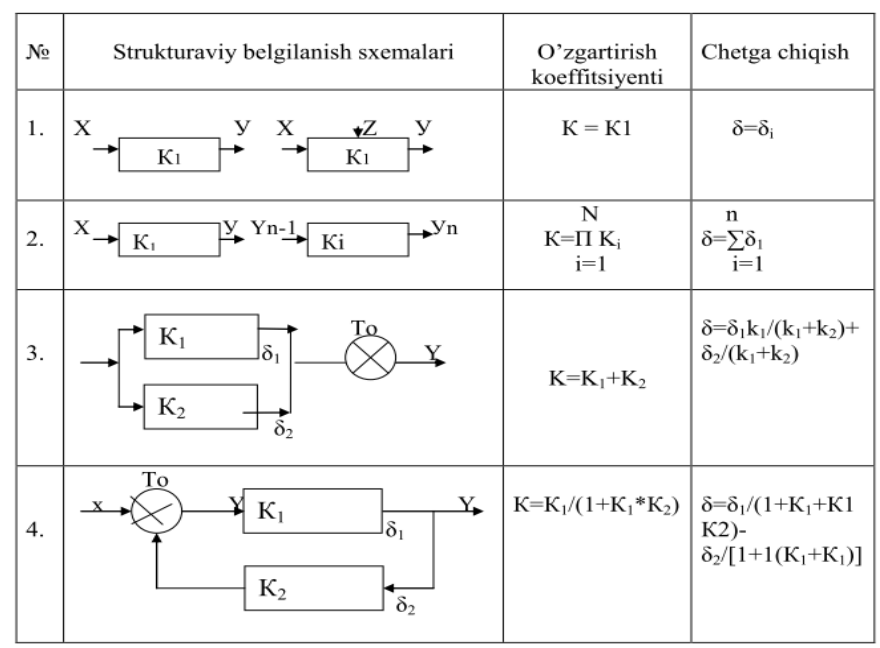

Structural designation scheme of the elements in automatic converter

Simple measuring converters (a) consist of a single element. In sequential converters (b), the input of the previous converter is the output of the next converter. The primary converter is usually called the sensitivity element (SE) and the final (next) converter is called the output element. The method of connecting sequential converters is used in conditions where it is convenient to use the output signal in a single change [1].

In automation and telemechanics systems, sensors act as a starting or measuring element. With their help, automated systems receive external information. The precise and reliable operation of the sensors determines the relevant key performance indicators of the entire system. Sensors should have high sensitivity and accuracy, long service life and precision at work, small size and weight, as well as low cost. 
Regardless of the type of sensors, they have the following basic technical requirements: accuracy, sensitivity, speed, reliability, price, size, weight. Conditionally, sensors can be thought of as consisting of receiver, intermediate, and actuator parts. The receiver part is affected by the change in the amount of input $\mathrm{x}$ and converts it to some intermediate quantity. This quantity is compared with the reference (sample) value of a similar physical quantity. Then, this sensor affects the executor part and forms the output $\mathrm{y}$ signal. The amount of input $\mathrm{x}$ is divided into electrical, thermal, mechanical, optical, acoustic, liquid and gas sensors depending on the physical composition. Electrical sensors current, voltage, power, frequency, magnetic flux; heat sensors - temperature and amount of heat; mechanical sensors - force, pressure, displacement, speed, acceleration; optical sensors - light intensity, illumination; acoustic sensors - sound power, its frequency, power; liquid and gas sensors - measure pressure and velocity. Each type of sensors with their study, recommendations and classifications to provide them with new, acceptance and service, this lead to division into new groups. Issues are divided into optical sensors, photoelectric, photoxymic, photothermal and photomechanical groups.

Another different type of sensors which is the output of them is determined by the physical nature of the quantity. The most common sensors are electrical, ie resistance, inductance, capacitance, current, voltage, phase, frequency sensors [2].

We can use semiconductor optical light receivers as sensitive elements. Currently, various models of semiconductor optical light receivers have been developed, which vary in function. The importance of optical light-sensitive elements in automated systems is enormous. These sensitive elements receive the incoming light and convert it into electrical signals in a photoelectric way. The optical sensor with the highest sensitivity in terms of spectral properties is the anomalous photo receiver (APV). Nowadays, it has been proven that an APV receiver can be made from any semiconductor material. However, the APV receiver made of any semiconductor material does not achieve high sensitivity. The advantage of APV receivers over other optical sensors is that they can operate autonomously. In other words, APV receivers do not require any electricity at all, they are self-sufficient in power by generating the finished light beam [3-5].

\section{CONCLUSION}

The use of photosensitive sensors in automated systems plays an important role in system optimization and ensures system stability. In general, the use of photosensitive sensors in automated systems plays an essential role with low energy consumption, noiseless operation, speed, high accuracy and reliability.

\section{REFERENCES}

[1] X.G'.Karimov, M.Q.Bobojanov // Avtomatik boshqarish va rostlash nazariyasi asoslari. T.: «Fan va texnologiya», 2015. -112 P.

[2] A.X.Jorayev, A.J.Xurramov / Boshqarish sistemalarining elementlari va qurilmalari // Ma'ruzalar matni. QARSHI - 2013.62 P.

[3] Alijanov D.D. Mirzaev K.S. / Preimushestva ispolzovaniya APV-elementov v avtomatizatsii // Avtomatika i programmnaya injeneriya. 2017, №2 (20)

[4] Alizhanov D.D., Rahimov N.R., ZHmud' V.A. / Razrabotka optojelektronnyh datchikov na osnove AFNplenok iz poluprovodnikovyh soedinenij //Sbornik nauchnyh trudov NGTU. - 2012. - №2 (68). - P. 3742.

[5] Coordinate-Sensitive Receiver /D.D. Alijanov, Sh.K. Bakhranov // International Journal of Research Studies in Electrical and Electronics Engineering(IJRSEEE) Volume 5, Issue 4, 2019, PP 17-22

Citation: Alijanov Donyorbek Dilshodovich, (2020)" Photosensitive Sensors in Automated Systems", International Journal of Modern Studies in Mechanical Engineering, 6(2), pp. 33-34. DOI: http://doi.org/ 10.20431/2454-9436.0602005

Copyright: (C) 2020 Authors, This is an open-access article distributed under the terms of the Creative Commons Attribution License, which permits unrestricted use, distribution, and reproduction in any medium, provided the original author and source are credited.

International Journal of Research Studies in Electrical and Electronics Engineering (IJRSEEE) Page | 34 